\title{
The influence of Internet shopping and use of credit cards on gender differences in compulsive buying
}

Internet shopping and compulsive buying

\author{
Changqin $\mathrm{Xu}$ \\ Faculty of Psychology, Southwest University, Chongqing, China \\ Alexander Unger \\ East Asia Institute, Ludwigshafen University of Business and Society, \\ Ludwigshafen, Germany \\ Chongzeng Bi \\ Faculty of Psychology, Southwest University, Chongqing, China \\ Julie Papastamatelou \\ Ludwigshafen University of Business and Society, Ludwigshafen, Germany, and \\ Gerhard Raab \\ Transatlantik Institut, Ludwigshafen University of Business and Society, \\ Ludwigshafen, Germany
}

\begin{abstract}
Purpose-Buying behavior has been significantly altered by technological developments as a result of the rise of the Internet. Online buying behavior is also inextricably linked to electronic payment systems, such as credit cards. This paper investigates how credit-card systems and online shopping increases compulsive buying of female and male consumers.

Design/methodology/approach - In the current study, the authors tested the influence of credit card possession and the role of Internet shopping on gender differences in compulsive buying in a representative German sample $(n=1,038)$. Binary logistic regression analysis and moderator analysis were applied.

Findings - As predicted, Internet shopping increased compulsive buying, but the association was the same for females and males. Further, credit card possession moderated the effect of gender on compulsive buying, with females showing a higher proneness to compulsive buying.

Originality/value - This research, which is based on a representative population study, contributes to the understanding of the role of credit cards and the one of online shopping in developing compulsive buying patterns among female and male consumers.
\end{abstract}

Keywords Compulsive buying, Credit cards, Electronic payment, Internet shopping, Gender differences Paper type Research paper

C Changqin Xu, Alexander Unger, Chongzeng Bi, Julie Papastamatelou and Gerhard Raab. Published in Journal of Internet and Digital Economics. Published by Emerald Publishing Limited. This article is published under the Creative Commons Attribution (CC BY 4.0) licence. Anyone may reproduce, distribute, translate and create derivative works of this article (for both commercial and non-commercial purposes), subject to full attribution to the original publication and authors. The full terms of this licence may be seen at http://creativecommons.org/licences/by/4.0/legalcode.

Funding: Funding from Research Center for Psychology and Social Development at Southwest University (Award Number: 18SKB004) is acknowledged by the authors.

Declaration of interest statement: No potential conflict of interest was reported by the authors.

Ethical approval: The ethical approval was waived by the ethics committee because the research involves no more than minimal risk to subjects.

Consent to participate: Consent form is used.
Received 19 November 2021 Revised 10 January 2022 Accepted 19 February 2022 


\section{JIDE 2,1}

\section{Introduction}

Buying behavior has been altered by two important modern developments. The first is the use of electronic payment systems, such as credit cards. In 1899, payments by credit or debit cards were first described in the utopian novel by romanticist Edward Bellamy in the context of a fictitious egalitarian society in the year 2000. Psychological research has rightly dedicated increasing attention to the psychological (cognitive, emotional and behavioral) effects of different payment types, such as cash, credit or debit cards and mobile phone payment (Boden et al., 2020; Wong and Lynn, 2017; Yu et al., 2020). The second significant development is the World Wide Web, which has been commercialized since the 1990s (Naughton, 2000) and has changed many aspects of human societies around the globe, including consumer behavior. Thus, online compulsive buying is of growing concern (Dittmar et al., 2007; Duroy et al., 2014; Lee and Park, 2008). It can be viewed as a new type of compulsive buying, as well as an enhancing factor of compulsive buying, which can be defined as an addictive behavioral buying pattern often accompanied by an intense preoccupation with the process of buying and feelings of gratification and relief during the process of buying, often followed by feelings of regret (Workman and Paper, 2010). The reasons for feelings of regret in compulsive buyers are numerous: It may be regret about the loss of money, debt or fears of conflict in relationships. However, the feeling of lack of control over compulsive buying tendencies remains central to feelings of regret (Lee and Workman, 2018) and guilt (Fan et al., 2020) in compulsive buyers. All these aspects may, in turn, initiate further extensive buying in order to continue to cope with such negative aversion feelings. Faber and Vohs (2004) view this as a vicious circle, where compulsive buying can be seen as a kind of paradoxical self-damaging behavior. The paradoxical character consists of repeated actions that have negative emotional effects, even though these effects are more or less accurately recognized by the actors themselves. During the process of or period before buying (compulsive buyers are often preoccupied with buying before actually doing so), these anticipated negative consequences are likely to be suppressed or ignored using any means possible by compulsive buyers.

\section{Literature and theoretical background}

\subsection{Compulsive buying and underlying mechanisms}

The major scope of the research on compulsive buying focuses on its association with personality traits; a vast number of studies identify a wide range of traits that seem to enhance the risk of developing a compulsive buying pattern (cf. for an overview Faber and O'Guinn, 2008). Many problematic personality traits can be seen as potential causes of an enhanced risk of developing a compulsive buying pattern (Workman and Paper, 2010). In contrast to compulsive buying, impulse buying is not planned and occurs on the spur of the moment (Mueller et al., 2019) and is understood as a "[ ... . ] reaction to an external trigger" (Chawla, 2020, p. 233). Compulsive buying is instead planned and intended to regulate emotions, mitigate anxiety or depression, or fade out negative sides of one's personality (Faber, 2010).

For a more comprehensive understanding of the compulsive buying phenomena, however, we still need at least two additional cornerstones. The first draws on the escape theory (Baumeister, 1991a, b). According to this approach, it is assumed that compulsive buying can be understood as a flight or escape from the problematic aspects of everyday life and perceived negative self-perception. According to this definition, the act of buying is applied as a distraction from negative aspects of a person's life or from negative parts of a person's self. The second cornerstone is the affinity of compulsive buyers to materialism. According to several studies (Dittmar, 2005a, b; Dittmar et al., 2007; Kyrios et al., 2004; Moulding et al., 2017), consumers seek to restore their deteriorated, uncertain, or threatened selves by purchasing and owning material goods. These explanations draw on symbolic self-completion theory (Elliott and Wattanasuwan, 1998; Gollwitzer and Wicklund, 1981; Wicklund and Gollwitzer, 1982). 
In this context, several authors broach the issue of compulsive buying as a consequence of an “empty self” (Cushman, 1990; Elliott, 1994; Scherhorn et al., 1990). Scherhorn (1990) even sees compulsive buying as driven by an "addictive trait". This can be described as alienation and atrophied social relationships, particularly in the younger generations.

Against the background of the described underlying mechanisms, we can summarize that most researchers agree that compulsive buying can be understood as a dysfunctional selfregulation strategy (Faber and Vohs, 2011) used to cope with negative aspects of the self (Workman and Paper, 2010; Maraz et al., 2016) and as an approach to regulate emotions (Faber and Christenson, 1996) that are highly connected to materialism (Dittmar et al., 2007).

\subsection{The relevance of online shopping to compulsive buying behavior}

With the development of Internet technology, the prevalence of online shopping is sharply increasing and has significantly influenced traditional compulsive buying. Thus, online compulsive buying behavior (Weinstein et al., 2015) is also of growing interest for researcher, and it is evident that the importance of online shopping has increased in recent decades. According to Zaharia (2019, p. 334) "[. . .] German online sales reached [in 2018] 65.10 billion euros representing $12.5 \%$ of total retail sales". It is worth considering, however, that the popularity of Internet shopping for some verticals, such as those for fashion and lifestyle products, is much higher (Statista, 2018 cited in Zaharia, 2019). According to a representative survey (VuMa, 2021), $67.1 \%$ of females and $69.0 \%$ of males in Germany reported that they were engaged in some form of online shopping in 2020. The frequency of online shopping did also not differ much between German females and males: For example, $51.2 \%$ of females and $48.8 \%$ of males reported being engaged in online shopping at least one or more times per month in 2019 (VuMa, 2020). Several studies support that online shopping reinforces compulsive buying proneness. A study by Adamczyk (2021) confirmed that "[...] online shoppers show a stronger susceptibility to compulsive buying than offline shoppers" among a representative sample of the Polish population (p. 9). Chen et al. (2004) emphasize that Internet-dependent individuals show a higher online shopping frequency. Further, Wang and Yang (2008) observed that online shopping is positively related to compulsive buying. This association is also supported by the findings of She et al. (2021). Dittmar et al. (2007) build a theoretical framework to explain this strong association between online shopping and compulsive buying as a result of materialistic values and in attempts to enhance one's selfimage or regulate one's emotions (cf. also Sharif et al., 2021).

As consistently shown in studies about "traditional" or "offline" compulsive buying, females show a higher prevalence of compulsive buying (Achtziger et al., 2015; Mueller et al., 2011a; Neuner et al., 2005; Unger et al., 2018; Unger and Raab, 2015). Moreover, the functions of buying, such as regulating emotions and negative aspects of one's personality, are often shown to be more relevant for female consumers (Dittmar et al., 2004). It is also reported that the aggravating effect of online shopping on compulsive buying is more pronounced for females compared to males. A study from China, for example, reported that the accelerating effect of online shopping on compulsive buying is significantly more pronounced in females compared to males (Wang et al., 2021). Another study with a Chinese sample has shown that higher levels of self-uncertainty leads to increased online compulsive buying among females but not among males (Liu et al., 2021). Hitherto, there are no representative data available about the gender differences in online compulsive buying in Germany. In the current representative samples, $3.5 \%$ of male and $10.2 \%$ of female participants were identified as compulsive buyers. Further, it is known that both general Internet usage and online shopping are more frequent for men (Dittmar et al., 2004). At the same time, for males, functional motives are more important, whereas for females, hedonistic, identity-related and emotionregulating motives are more important (Dittmar, 2000, 2001; Dittmar and Drury, 2000).

\section{Internet shopping and compulsive buying}


JIDE

Because of this reason and because of the higher prevalence rates of females in the case of traditional offline compulsive buying, it can be assumed that online shopping will be more problematic for females, and as a consequence, females will also show higher prevalence rates.

To summarize, shopping online is a substantial risk factor for compulsive buying and shopping online may have an accelerating effect on the development of compulsive buying patterns, especially for women. At the same time, consumers who are already compulsive buyers may be strongly attracted to the fast and easy delivery opportunities offered by online shopping. The attractiveness of online shopping for compulsive buyers also depends highly on electronic payment procedures, which we will address later.

Online compulsive buying is seen as highly related to Internet addiction (Suresh and Biswas, 2020), and studies report a relationship between excessive Internet usage and compulsive buying (Claes et al., 2012; Raab and Neuner, 2008; She et al., 2021; Lee et al., 2016; Mueller et al., 2011a, b; Sharif and Khanekharab, 2017). Further, a study by Zheng et al. (2020b) reports that online usage of network sites by women is associated to compulsive buying. The results of a study by Trotzke et al. (2015) suggest that online compulsive buying can even be understood as a specific form of Internet addiction. A close relationship between Internet addiction and compulsive buying can easily be understood when one considers that the causes of Internet addiction seem to be very similar to those of compulsive buying behavior. For example, a study by Hsieh et al. (2019) identifies selfidentity confusion as a cause of Internet addiction. At the same time, studies have shown an association between identity confusion and compulsive buying (Moulding et al., 2021; Sharif and Khanekharab, 2017). Liu et al. (2021) observed that the related construct of selfuncertainty also increases online compulsive buying among females. The association of Internet addiction with online compulsive buying is reported in the context of the materialism of fashion-oriented young consumers (Bhatia, 2019; Sharif and Yeoh, 2018). Materialism and financial comparisons are also observed to mediate the relationship between heavy social networking and online compulsive buying (Sharif et al., 2021). There are several reasons for the connection between Internet usage and proneness to compulsive buying. Adamczyk (2021) summarizes them in the following ways: firstly the process of buying is easier online and the need for buying can be initiated immediately and only depends on a few technical preconditions, such as Internet access or an electronic payment system; secondly, anonymity may also play an important role, and the compulsive buyer may be able to hide their excessive buying habits from family members or partners for at least a short period of time. It is particularly evident that Internet shopping enables consumers to shop at any time of day and largely also from any location. This means that those individuals experiencing an impulse to buy can immediately surrender to this impulse. This may have a similar increasing effect on compulsive buying to electronic payment (Mueller et al., 2011b). Furthermore, anonymous shopping on the Internet "[ ... ] enables compulsive buyers to avoid unwanted social interactions (Mestre-Bach et al., 2017, p. 231). Similarly, Kiss and Veres (2017, p. 52), emphasizing that compulsive buyers not only strive to avoid social interactions, but also endeavor to experience immediate positive emotions. Both of these can make online shopping attractive to compulsive buyers. Another cause may be that younger consumers are more prone to compulsive buying behavior while also having a higher affinity to Internet usage compared to older consumers (Eroglu and Kocatürk, 2020).

Beyond the described specific characteristics of online compulsive buying, studies have also identified similarities between online and "traditional" compulsive buying. For example, Zheng et al. (2020a) identified stress as a cause for online compulsive buying among female consumers. The same study showed that self-esteem is another important moderating factor of influence. All mentioned factors are well documented for "traditional" compulsive buying. 
To summarize, online buying can be assumed to be an increasing driver of compulsive buying patterns.

One reason that is missing in this summary of important causes is that online shopping is more critical for compulsive buying because of the inevitability of having to pay electronically. While several types of electronic payment system can be optionally applied in traditional shops, they are necessary for online shopping. The theoretical background of electronic payment systems, such as credit cards, as another important enhancing factor of compulsive buying will be described in the next section.

\subsection{The relevance of electronic payment to compulsive buying behavior}

Electronic payment has contributed to the emergence and increase of compulsive buying because of the two main reasons. First, the consumer does not feel the same amount of loss as when paying by cash. Namely, the avoidance of the pain as experienced by paying in cash (Prelec and Loewenstein, 1998) can make electronic payment attractive to compulsive buyers. Due to the more abstract character of electronic payment, consumers may not recognize to the same extent that their current amount of money is reduced. Second, in the case of credit cards, there is also the delay of payment until the end of the month. Both deceive the consumer in relation to the degree of expenditure. Studies have demonstrated that consumers paying electronically systematically underestimate their expenditures compared to those making cash payments (Raab, 1998; Soll et al., 2013) and show an increased willingness both to pay and to take new debts (Prelec and Simester, 2001; Falk et al., 2016). It can be assumed that these described mechanisms facilitate compulsive buying. This is of high relevance for our current study because buying on the Internet inevitably involves electronic payment.

Electronic payment has been discussed as a potential factor of influence on problematic buying behavior. Various studies have confirmed that electronic payment can lead to significant underestimation of the amount of money spent, compared to cash payments, as well as enhanced willingness to spend money. Enhanced spending when using a credit cards, for example, is well documented in several studies (Kamleitner and Erki, 2013; Prelec and Simester, 2001; Runnemark et al., 2015). Feinberg (1986) explained the enhanced spending effect when using a credit card by learning through condition. Soman (2001) reported confirming effects for two mechanisms. The first of these is the rehearsal of the amount, where if the amount spent had been written down, the buying intention was reduced. The same was observed for the second mechanism, the factor of delay; if payment was to be processed immediately, the buying intention was again reduced. In particular, the last effect is of relevance for payment with credit cards. In addition, and contrary to the observed enhanced spending behavior, it is also well documented that consumers underestimate their expenses when using credit cards or other electronic payment systems (Raab, 1998) compared to those paying cash. The underlying effect has not been sufficiently explained yet, but several explanations can be given. The payment can be understood as an aversive and painful process (Harnish et al., 2021). Although it is observed that payment is experienced less painfully for compulsive buyers (Harnish et al., 2018), it is widely assumed that compulsive buyers do use credit card and other electronic payment systems to further avoid the pain of payment. The psychological distance created by paying electronically enables them to be less affected by aversive feelings about paying. In turn, it can be assumed that credit cards or other electronic payment systems have two consequences. First, as shown by Raab (1998), consumers underestimate their spending levels if the payments were conducted with credit cards instead of cash. Paying by credit cards enables consumers to suppress any emotional disturbance resulting from paying and thus also increases the debt risk of consumers (Livingstone and Lunt, 1992). Second, it can be assumed that credit cards or other electronic payment systems accelerate the processes of becoming a compulsive buyer. This might be 
particularly true for online purchases because this type of shopping makes it possible for consumers to shop from any location $24 / 7$, as long as a mobile phone or a laptop with Internet access is available. To summarize, on the one hand, it has been postulated that the use of credit cards, etc. can have a facilitating effect on money expenditure; on the other hand, it has been postulated that people with compulsive buying symptoms might prefer to use credit cards in order to pursue their compulsive buying with less hindrance.

In the next section, we will outline which research gap we intend to close with the current study. Afterward, we will derive the hypotheses from theoretical considerations, which describe the assumed underlying mechanism of electronic payment systems and online shopping and how it is related to compulsive buying and gender differences in compulsive buying.

\section{Theoretical framework and hypothesis}

\subsection{The purpose and importance of the current study}

Credit cards are used more by men than women, but the difference has diminished in recent years; representative data for 2020 revealed that $53 \%$ of females and $63 \%$ of males in Germany were credit card owners (Bundesbank, 2021, p. 50). The same survey showed that PayPal is the most popular and credit cards are the second popular electronic payment method. Another finding revealed that credit card usage increases with higher payment amounts (Bundesbank, 2021; slide 30). A positive association between compulsive buying and enhanced credit card use has been reported in various studies. For example, a recent study by Khandelwal et al. (2021) confirmed a strong association between credit card use and compulsive buying. The use of credit cards is often assumed to be a consequence of enhanced materialistic values, which have been identified as one important cause of compulsive buying (Dittmar et al., 2007; Richins, 2011; Tarka, 2020). For example, Pradhan et al. (2018) draw on an online sample of adult credit card owners in India, confirming a positive association between credit card use and compulsive buying. Another study from India, which used a convenience sample (Khandelwal et al., 2021), also observed that credit card use increased compulsive buying tendencies. In addition, with other studies dealing mainly with student samples (e.g. Jiang and Shi, 2016; Maccarrone-Eaglen and Schofield, 2020; Nga et al., 2011), it was confirmed that credit cards or other electronic payment systems facilitate compulsive buying tendencies. It has been indicated that credit cards seem to be a facilitating factor for compulsive buying across different samples and cultural settings, but to our knowledge, there is no previous study testing this association with a representative sample. Those studies dealing with the role of credit cards in compulsive buying among college students or adult convenience samples show inconsistent results; several studies report an increasing effect of compulsive buying (c.f. Maccarrone-Eaglen and Schofield, 2020), whereas others, for example Khare (2013), observed no influence. The best way to test the question as to whether the possession of credit cards is a critical factor for compulsive buying is by testing it with a representative sample.

Throughout most studies, women show a higher compulsive buying rate compared to men (Maraz et al., 2016). Further, indebtedness as one of the severe consequences of compulsive buying is particularly enhanced among women and those individuals who possess numerous credit cards (de Matos et al., 2019). Consequently, it would be important to know whether the effects of credit card usage differ for men and women in a representative study. We assume that credit cards might contribute to explaining gender differences in compulsive buying and predict that they will moderate the influence of gender on compulsive buying. A higher vulnerability of female consumers for online compulsive buying has been reported by Zhang et al. (2019), who show that Chinese college students are highly affected by online compulsive buying proneness. This study also confirms that female students are more engaged in online shopping than their male counterparts. Similar results are reported by 
another study with a student sample from Romania (Bighiu et al., 2015), which confirms the high vulnerability of young female consumers to online compulsive buying.

To summarize, for buying behavior in general and for compulsive buying in particular, Internet shopping and credit card payments may have intensifying or fundamentally modifying effects. Besides the parallel use of credit cards and cash in shops, the online purchase process is necessarily connected to one of different possible electronic payment systems. The newest development, however, is the payment by smartphones or related devices. In the current study, which is based on a representative sample of the German population, we intend to investigate the role of possessing one or more credit cards and the importance of online buying on the risk of being a compulsive buyer.

We investigate two new aspects in the current study: 1) The study is the first that considers credit card use in relation to gender differences in compulsive buying based on a representative sample; 2) We assume that the compulsive buying facilitating effect of credit cards is more pronounced for women, with their higher affinity for compulsive buying, than for men. Thus, we test a moderation effect of the variable of credit card possession on the effect of gender on compulsive buying. We also investigate whether enhanced Internet shopping can explain higher compulsive buying by women compared to men.

\subsection{Hypothesizing on credit cards, Internet buying, compulsive buying and gender}

To summarize, our study has two purposes: first, we investigate the role of credit cards and Internet buying on compulsive buying behavior in a representative study of the German population; second, we test whether these two aspects play a substantial role in moderating gender differences in compulsive buying. Gender differences with higher compulsive buying rates among women are reported in the majority of conducted studies (cf. Dittmar, 2005a; Maraz et al., 2016) and have been observed in representative studies (e.g. Otero-López and Villardefrancos, 2014) as well as in cross-cultural student samples (e.g. Unger et al., 2018).

Based on the outlined theoretical consideration, our hypotheses are as follows:

H1. The use of Internet shopping increases compulsive buying proneness and the probability of being a compulsive buyer.

H2. The possession of one or more credit cards increases compulsive buying proneness and the probability of being a compulsive buyer.

H3. The possession of one or more credit cards moderates the influence of gender on compulsive buying proneness.

H4. Internet shopping moderates the influence of gender on compulsive buying proneness.

\section{Materials and method}

\subsection{Procedure and sample}

The survey of the current study was conducted by a professional market research institute (TNS Emnid). The age of the target population was from 14 years onwards. The selection procedure was based on multilevel sampling (ADM master sample), which was developed by Behrens and Löffler (1999). All areas of Germany were covered. The random sample was made up by $n=1,038$ in total, while $4.1 \%$ of the cases (43 cases) were incomplete and, therefore, removed from the analysis. The survey was conducted in the form of laptop-supported face-to-face interviews.

\subsection{Material}

German compulsive buying scale (GCBS): The measurement instrument used for the detection and classification of compulsive buying propensity was the GCBS (Raab et al., 2005;

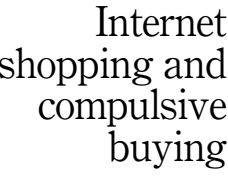

33 
JIDE

Scherhorn et al., 1992). This 16-item measurement instrument, which presents response options from 1 to 4 , is added up into an aggregate score ranging from 16 to 64 . The individual items consist of a 4-level Likert scale, with the continuum "completely disagree" (1) and "completely agree" (4). The compulsive buying index is calculated by summing up all sixteen response values (ranging from 1 to 4 ) resulting in a range from 16 (lowest possible compulsive buying proneness to 64 (highest possible compulsive buying proneness).

Although the one-dimensional structure of the scale was demonstrated in the validation study by Raab et al. (2005), the items capture different facets of compulsive buying. This is in line with Ridgeway et al. (2008), who assume that compulsive buying does include "[ ...] elements of both obsessive-compulsive and impulse-control disorders [ . . ]" (p. 623). Several items refer to uncontrollable urges to buy, which also include reactive elements.

These items present the impulse control disorder aspect of compulsive buying. Examples of this facet are "As soon as I enter a shopping center or mall, I have an irresistible urge to go to a shop and buy something" (Item 2) or "Sometimes I see a product and feel a strong irresistible impulse to buy it" (Item 4). The second aspect refers to the obsessive-compulsive aspect. Example items are "Often I have the feeling to own a certain item by any means" (item 5) and "There are times when I go shopping just for fun" (item 8). Finally, the scale captures the aspect of averse consequences and emotional post-purchase regret of compulsive buying. This aspect is presented in the examples "I have often bought something that I did not use at all afterwards" (item 10) and "At times, I've felt somewhat guilty after buying a product, because it seemed unreasonable" (item 15). For the German original items see Raab et al. (2005). The feelings of regret imply new arising negative feelings, which often lead to new acts of buying in order to regulate these negative feelings (cf. Lee and Workman, 2021). The instrument has already been used in many studies in the German-speaking context (Achtziger et al., 2015; Neuner et al., 2005; Raab et al., 2011). The reliability of the scale was very high as indicated by $\alpha=0.94$. The GCBS enables a second important measurement: the classification of consumers with acute compulsive buying propensity has been defined as a scoring of two standard deviations above the respective middle value. The area indicating marked compulsive buying propensity, resides between one and two standard deviations of the middle value (cf. Raab et al., 2005). All individuals scoring above 45 have been identified as being at high risk of compulsive buying. Thus, we have two different dependent measurements reported in the current study: first, the aggregated score of compulsive buying, referred to as compulsive buying proneness, and second, the dichotomous variable of scoring above the critical threshold of 45 and thus being or not being at high of risk of compulsive buying.

Possessing a credit card, Internet shopping and sociodemographic variables: Besides the compulsive buying and the measurement of sociodemographic variables, the survey also asked about the use of electronic payment systems and the perceived individual importance of Internet shopping.

For electronic payment systems, we have focused on credit cards, which were defined as Master-Card, VISA, American Express and Diners Club. The participants were asked, "Which of the following credit cards do you possess?" and the four mentioned types of credit cards were presented with a "yes-no" response format. The self-assessment via the question "I have the feeling that with the possibility of Internet shopping I buy more than without that possibility" captures the importance of online shopping and has a 4-point Likert-type response format ranging from 1 (= not true) to 4 (= very true). We abbreviate the item in the following with the term "Internet shopping".

\section{Results}

We observed a mean score of $M_{\mathrm{GCBS}}=26.43(S D=10.17)$. Further $6.8 \%$ participants of this sample were identified as compulsive buyers by scoring above the threshold value of 45 . 
Women showed a significant higher proneness to compulsive buying compared to men. $\left(M_{\mathrm{WOMEN}}=28.85 ; S D=10.95\right.$ vs. $\left.M_{\mathrm{MEN}}=23.75 ; \mathrm{SD}=8.47, p<0.001\right)$. Further we observed that $10.0 \%$ of the women and $3.3 \%$ of the men were identified as compulsive buyers.

Regarding the first hypothesis, an ANOVA was conducted with the factor "Internet shopping". The compulsive buying index was the dependent measurement and age, a covariate. A significant influence for "Internet shopping" was observed, $F(3,643)=68.76$, $p<0.001$. The more the item was accepted, the more pronounced the compulsive buying index was. Moreover, the covariate age reached significance, $F(1,643)=7.00, p=0.008$.

In order to verify the influence on compulsive buying probability, a corresponding binary logistic regression was conducted with the dichotomous dependent variable being at risk for compulsive buying. This yielded that the increment from 1 to 2 was not significant $(B=0.92$, $p=0.113)$, where all further increments from 1 to $3(B=2.20, p<0.001)$ and 1 to $4(B=3.11$, $p<0.001$ ) obtained significance (cf. Table 1). The individual probabilities (cf. Figure 1)

\begin{tabular}{llccc}
\hline Variable & $B$ & $S E$ & Odds ratio & Wald statistics \\
\hline Internet (reference: not at all) & - & - & - & $47.14^{* * * *}$ \\
Internet (2) & 0.92 & 0.58 & 2.51 & 2.51 \\
Internet (3) & 2.20 & 0.47 & 8.98 & $21.92^{* * *}$ \\
Internet (4) & 3.11 & 0.48 & 22.41 & $41.77^{* * *}$ \\
Constant & -2.37 & 0.18 & 0.09 & $164.97^{* * *}$
\end{tabular}

Note(s): $* * * p<0.001$
Internet shopping and compulsive buying

Table 1. Binary logistic regression analysis predicting risk for compulsive buying as function of Internet shopping

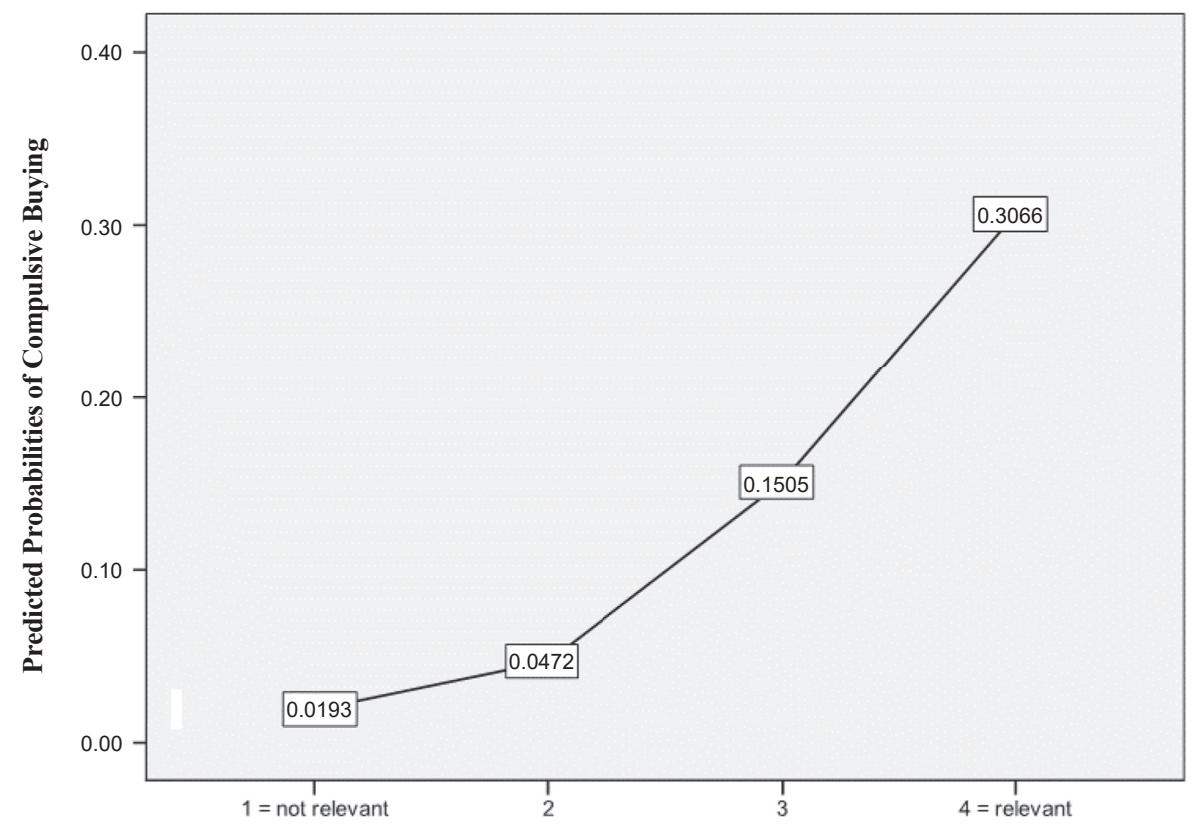

Perceived Role of "Internet Shopping" for Increased Expenditures

Note(s): The predicted probabilities refer to being a compulsive buyer as defined scoring above the threshold of 45 by the German Compulsive Buying Scale (GCBS)
Figure 1. Probability of being a compulsive buyer by the perceived role of "Internet shopping" for increased expenditures 
JIDE

36

Table 2.

Binary logistic regression analysis predicting risk for compulsive buying as function of possessing credit cards (yes/no) amounted to $1.9 \%$ (1), $4.7 \%$ (2), $15.0 \%$ (3) and 30.7\% (4). This confirms that with a perceived increase in the role of the Internet for multiple purchases ("Internet shopping"), the percentage proportion of compulsive buying increases significantly.

With respect to the second hypothesis, we tested the influence of the status of possessing credit cards (possessing one or more credit cards vs. not possessing any) on compulsive buying proneness, including age as a covariate. A significant influence was observed for credit card status, $F(1,989)=10.84, p=0.001$. Again, the covariate age reached significance, $F(1,989)=54.32, p<0.001$. We then tested the influence of the status of possessing credit cards on the risk of being a compulsive buyer (scoring above the threshold value) by conducting a binary logistic regression. We observed no significant effect of status of possessing credit card (yes/no), $B=0.42, p=0.145$; (cf. Table 2 ). Thus, our second hypothesis could only be confirmed for compulsive buying proneness and not for the influence on the probability of being a compulsive buyer.

Furthermore, we tested the moderation of credit cards and "Internet shopping" on the compulsive buying of women and men, respectively, in the third and fourth hypotheses. Prior to this, we also tested if there were differences in the two variables between female and male consumers. Male consumers had one or more credit cards more often than female consumers $\left(M_{\text {MALE }}=0.29\right.$ vs. $\left.M_{\text {FEMALE }}=0.22 ; p=0.012\right)$, whereas no gender differences were observed for "Internet shopping" $\left(M_{\mathrm{MALE}}=1.57\right.$ vs. $\left.M_{\mathrm{FEMALE}}=1.63 ; p=0.373\right)$.

To test our third hypothesis, we conducted a moderation analysis with gender (male $=1$, female $=2$ ) as independent variable and possessing one or more credit cards (yes $=1$, no $=1$ ) as moderator by using the PROCESS-macro by Hayes (2013) for SPSS 24.

The interaction credit card by gender was significant; $b_{3}=2.87, p=0.028$. (cf. Table 3 ). Thus, as predicted, we observed that credit card possession moderated the gender influence on compulsive buying proneness: If a credit card was possessed, women showed a stronger compulsive buying proneness compared to men. If no credit-card was possessed, this effect was still significant but weaker: according to the conditional effects analysis (cf. Figure 2), the increase of compulsive buying for women was higher if one or more credit cards were possessed $\left(\right.$ effect $t_{\text {CREDIT-CARDS }}=7.12 ; t(1,991)=6.54, p<0.001 ; \mathrm{BC} 95 \% \mathrm{CI}$ : LLCI $=4.99$, $\mathrm{ULCI}=9.26$ ), compared to a weaker increase of compulsive buying for women if no credit card was possessed (effect NO_CREDIT-CARDS $=4.25 ; t(1,991)=5.94, p<0.001 ; \mathrm{BC} 95 \% \mathrm{CI}$ : $\mathrm{LLCI}=2.85$, ULCI $=5.66$ ).

In addition, we conducted a reversed moderation analysis with gender as moderator and credit cards as independent variable on compulsive buying proneness (cf. Table 4). The

\begin{tabular}{lcccc}
\hline Variable & $B$ & $S E$ & Odds ratio & Wald statistics \\
\hline Credit cards & 0.42 & 0.29 & 1.53 & 2.13 \\
Constant & -2.73 & 0.15 & 0.07 & $353.52^{* * *}$ \\
Note(s): $* * * p<0.001$ & & & & \\
\hline
\end{tabular}

Table 3.

Moderation with credit cards (yes/no) as moderator on the influence of gender on compulsive buying proneness

\begin{tabular}{lrrrr}
\hline & Coeff & SE & \multicolumn{1}{c}{$t$} & \multicolumn{1}{c}{$p$} \\
\hline Intercept & 18.926 & 1.162 & 16.283 & $<0.001$ \\
Gender & 4.252 & 0.716 & 5.941 & $<0.001$ \\
Credit card (yes/no) & -2.412 & 2.055 & -1.174 & 0.241 \\
Gender x credit card (yes/no) & 2.872 & 1.303 & 2.205 & 0.028 \\
Note(s): $p$-values are for two-tailed tests & & & & \\
\hline
\end{tabular}


corresponding conditional effects showed a moderation effect: possessing a credit card enhanced the compulsive buying proneness for women effect $t_{\text {WOMAN }}=3.33 ; t(3,991)=3.60$, $p<0.001$; BC95\%CI: LLCI $=1.52$, ULCI $=5.15$ ) but not for men effect $t_{\mathrm{MEN}}=0.46$; $t(3,991)=0.50, p=0.617$; BC95\%CI: LLCI $=-1.34, \mathrm{ULCI}=2.26)$ (cf. Figure 2).

To examine the fourth hypothesis, we conducted another moderation analysis with gender (male $=1$, female $=2$ ) as independent variable and "Internet shopping" (ranging from 1 to 4 ) as moderator. We observed that the main effects of gender, $b_{1}=3.83, p=0.002$ and "Internet shopping", $b_{1}=3.33, p=0.002$ ), reached significance. The interaction, however, was not significant, $b_{3}=1.01, p=0.125$. "Internet shopping" did not moderate the influence of gender on compulsive buying proneness.

\section{Conclusions}

The main results can be summarized as follows. First, "Internet shopping" was confirmed to have an enhancing effect on compulsive buying (H1). The effect was observed for compulsive buying proneness, as well as for the scoring above the critical threshold value for being at risk for compulsive buying. If online shopping must be evaluated as a facilitating external factor, or as part of the compulsive buying construct itself, it should be clarified in future research. In contrast, according as the significant main effect of credit cards on compulsive buying was observed for compulsive buying proneness, but not for the risk of being a compulsive buyer (H2). Testing the two hypotheses on gender differences in compulsive buying (H3 and H4), with credit card possession and "Internet shopping" as moderators, we can conclude that credit card possession moderates the effect of gender on compulsive buying: the higher compulsive buying proneness of woman compared to men was more pronounced in the group who possessed one or more credit cards. We also observed a reversed significant moderation. Future research is needed to clarify which of the two moderation models explained the underlying valid mechanism better. According to "Internet shopping", no moderation was observed. We conclude that electronic payment systems are particularly problematic for women, who already show a higher compulsive buying vulnerability as has been observed in most related studies (cf. Maraz et al., 2016). Our observation is in line with research that has shown that consumers who pay with electronic payments consistently underestimate their
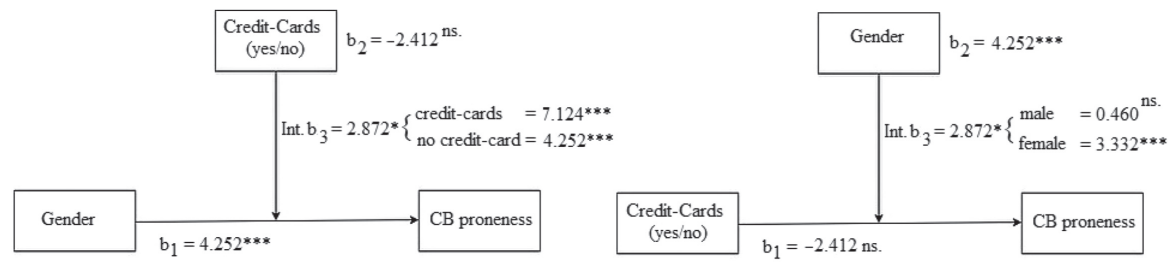

Note(s): $n s=$ non significant; $* * *=p<0.001 ;$ Int $=$ interaction

\begin{tabular}{llrrrr}
\hline & & Coeff & SE & $t$ & $p$ \\
\hline Intercept & i1 & 18.925 & 1.162 & 16.2 & $<0.001$ \\
Credit card (yes/no) & b1 & -2.412 & 2.055 & 5.941 & 0.241 \\
Gender & b2 & 4.252 & 0.716 & -1.174 & $<0.001$ \\
Credit card (yes/no) by gender & b3 & 2.872 & 1.303 & 2.205 & 0.028
\end{tabular}

Internet shopping and compulsive buying
Figure 2.

Moderation with credit cards (yes/no) as moderator on the influence of gender on compulsive buying proneness (left) and the reversed moderation with gender as moderator on the influence of gender on compulsive buying proneness (right)

Table 4. Moderation with gender as moderator on the influence of credit cards (yes/no) on compulsive buying proneness (reversed moderation)

Note(s): $p$-values are for two-tailed tests 
expenditures (Raab, 1998) and that electronic payment leads to enhanced expenditures (Feinberg, 1986; Prelec and Simester, 2001; Soman, 2001). Our study could help to initiate the reinterpretation and retesting of similar studies on the influence of credit cards or other electronic payment systems on compulsive buying. For example, a study by Nofario et al. (2020) shows no moderating role of credit cards on the influence of money power, prestige, money distrust, or money anxiety on compulsive buying. Our results, however, suggest that the role of credit cards should generally be differentiated for female and male consumers because we observe credit cards as a moderator of the gender effect on compulsive buying. Another study by Khandelwal et al. (2021) confirms that more frequent credit card usage is associated with higher levels of compulsive buying proneness. Both, in turn, are associated with lower financial literacy. Our results suggest that the role of credit cards should, however, be generally differentiated for female and male consumers because we observed credit cards as a moderator of the gender effect on compulsive buying. Two questions that remain open are whether consumers and, in particular, female consumers who use credit cards (or other electronic payment systems) will easily or more quickly develop compulsive buying patterns, and whether consumers who have already developed compulsive buying patterns are more likely to possess one or more credit cards more.

What is known from functional magnetic resonance imaging (fMRI) studies is that electronic payment methods among non-compulsive (Ceravolo et al., 2019) and compulsive buyers (Raab et al., 2010, 2011) display a reduced BOLD activity in the brain region of the insula, compared to payment by cash. "[...] its activation is generally associated with negative emotions such as fear, anger, disgust, pain” (Ceravolo et al., 2019, p. 4). These authors also summarize that they "found a significant greater activation of insula in the cash than in card or smartphone conditions" (p. 4). What can be labeled as an inhibiting factor of money expenditure in the case of cash money was obviously bypassed in the case of electronic payment systems because the insula was less activated and, consequently, consumers did not experience the described negative emotions when spending money. Therefore, electronic payment systems can be evaluated as a problematic factor of compulsive buying, particularly for female consumers. With respect to "Internet shopping", we observed a main effect on compulsive buying, but no moderation effect on the influence of gender on compulsive buying. One explanation for this observation could be the assumption that the ambiance of shopping malls and other shops might still play an important role for female consumers. This might also be important for those women who are prone to compulsive buying. These explanations are preliminary and speculative and need to be tested in future research. It can be summarized that the observed main effect indicates that "Internet shopping" is of relevance to compulsive buying in both female and male consumers. We present the evaluation-of these gender-related conclusions on the role of "Internet shopping" as preliminary and recommend that the relationship be retested in future studies.

Several consumer policy implications of our results are conceivable. Consumer protection may emphasize the risk of using credit cards, particularly for young female consumers. Policy implications may also imply warning labels on Internet pages during the process of payment with credit cards or related paying systems about the underestimations of expenses, risk of overconsumption and possibility of indebtedness. Most importantly, young consumers could be taught about consumer and financial competency so that they have a greater awareness of the potential financial pitfalls associated with modern consumer culture. This could be included in the curriculum of schools and high schools.

\section{Limitations}

The last aspect brings us to the limitations of the current study. We have measured the perceived role of "Internet shopping" for increased expenditure as a self-reported measure. 
Thus, measurement biases are possible. Another limitation of the current study is that we did not measure the frequency of credit card usage. It is, for example, well known that some consumers only use credit cards for specific purposes such as hotel or flight-bookings. Furthermore, we have focused on credit cards as a relatively established payment system and did not measure other more innovative electronic payment systems. Future studies are needed to clarify whether Internet compulsive buying is fundamentally different from "offline" compulsive buying in this regard.

In summary, we can conclude that the current study clearly confirmed that compulsive buying can increase due to "Internet shopping" as a main effect without gender differences, and that credit card possession is an increasing risk factor for compulsive buying for women but not for men. The strength of the current study is that it is based on representative data. Nonetheless, we suggest replication to retest the observed effects. The high importance of potential applications lies in the continuously increasing relevance of electronic payment systems and Internet shopping. If the characteristics of these aspects can be better understood, consumers could be better protected from falling into the traps of the modern consumer world.

\section{References}

Achtziger, A., Hubert, M., Kenning, P., Raab, G. and Reisch, L.A. (2015), "Debt out of control: the links between self-control, compulsive buying, and real debts", Journal of Economic Psychology, Vol. 49, pp. 141-149, doi: 10.1016/j.joep.2015.04.003.

Adamczyk, G. (2021), "Compulsive and compensative buying among online shoppers: an empirical study", PLoS ONE, Vol. 16 No. 6, e0252563, doi: 10.1371/journal.pone.0252563.

Baumeister, R.F. (1991a), "The self against itself: escape or defeat", in RebeccaCurtis, C. (Ed.), The Relational Self: Theoretical Convergences in Psychoanalysis and Social Psychology, Guilford, pp. 238-256.

Baumeister, R.F. (1991b), Escaping the Self: Alcoholism, Spirituality, Masochism, and Other Flights from the Burden of Selfhood, Basic Books, New York.

Behrens, K. and Löffler, U. (1999), “'Aufbau des ADM-Stichproben-Systems' [The structure of the ADM sample system]", in ADM Arbeitskreis Deutscher Markt- und Sozialforschungsinstitute e.V. (Ed.), ADM Arbeitskreis Deutscher Markt- und Sozialforschungsinstitute e. StichprobenVerfahren in der Umfrageforschung, VS Verlag für Sozialwissenschaften.

Bhatia, V. (2019), "Impact of fashion interest, materialism and internet addiction on e-compulsive buying behaviour of apparel", Journal of Global Fashion Marketing, Vol. 10 No. 1, pp. 66-80, doi: 10.1080/20932685.2018.1544502.

Bighiu, G., Manolică, A. and Roman, C.T. (2015), "Compulsive buying behavior on the internet", Procedia Economics and Finance, Vol. 20, pp. 72-79, doi: 10.1016/S2212-5671(15)00049-0.

Boden, J., Maier, E. and Wilken, R. (2020), "The effect of credit card versus mobile payment on convenience and consumers' willingness to pay", Journal of Retailing and Consumer Services, Vol. 52, p. 101910, doi: 10.1016/j.jretconser.2019.101910.

Bundesbank, D. (2021), Payment Behaviour in Germany in 2020 - Making Payments in the Year of the Coronavirus Pandemic Survey on the Use of Payment Instruments, Deutsche Bundesbank Eurosystem, Frankfurt/Main.

Ceravolo, M.G., Fabri, M., Fattobene, L., Polonara, G. and Raggetti, G. (2019), "Cash, card or smartphone: the neural correlates of payment methods", Frontiers in Neuroscience, Vol. 13, pp. 1-9, doi: 10.3389/fnins.2019.01188.

Chawla, A. (2020), "Role of Face book video advertisements in influencing the impulsive buying behavior of consumers", Journal of Content, Community and Communication Amity School of Communication, Vol. 11, pp. 231-246.

\section{Internet shopping and compulsive buying}


JIDE

Chen, K., Tarn, J.M. and Han, B.T. (2004), "Internet dependency: its impact on online behavioral patterns in e-commerce”, Human Systems Management, Vol. 23 No. 1, pp. 49-58, doi: 10.3233/ mHSM-2004-23104.

Claes, L., Müller, A., Norré, J., Assche, L., Wonderlich, S. and Mitchell, J.E. (2012), "The relationship among compulsive buying, compulsive internet use and temperament in a sample of female patients with eating disorders", European Eating Disorders Review, Vol. 20 No. 2, pp. 126-131, doi: 10.1002/erv.1136.

Cushman, P. (1990), "Why the self is empty: toward a historically situated psychology", American Psychologist, Vol. 45 No. 5, pp. 599-611, doi: 10.1037/0003-066X.45.5.599.

de Matos, C.A., Vieira, V., Bonfanti, K. and Mette, F.M.B. (2019), "Antecedents of indebtedness for lowincome consumers: the mediating role of materialism", Journal of Consumer Marketing, Vol. 3, pp. 92-101, doi: 10.1108/JCM-09-2017-2352.

Dittmar, H. and Drury, J. (2000), "Self-image - is it in the bag? A qualitative comparison between "ordinary" and "excessive" consumers", Journal of Economic Psychology, Vol. 21 No. 2, pp. 109-142, doi: 10.1016/S0167-4870(99)00039-2.

Dittmar, H., Long, K. and Meek, R. (2004), "Buying on the internet: gender differences in on-line and conventional buying motivations”, Sex Roles, Vol. 50 Nos 5/6, pp. 423-444, doi: 10.1023/B:SERS. 0000018896.35251.c7.

Dittmar, H., Long, K. and Bond, R. (2007), "When a better self is only a button click away: associations between materialistic values, emotional and identity-related buying motives, and compulsive buying tendency online", Journal of Social and Clinical Psychology, Vol. 26 No. 3, pp. 334-361, doi: $10.1521 /$ jscp.2007.26.3.334.

Dittmar, H. (2000), “The role of self-image in excessive buying”, in Benson, A. (Ed.), I Shop, Therefore I Am: Compulsive Buying and the Search for Self, Aronson, pp. 105-132.

Dittmar, H. (2001), "Impulse buying in ordinary and compulsive consumers", in Baron, J., Loomes, G. and Weber, E. (Eds), Conflict and Tradeoffs in Decision-Making, Cambridge University Press, pp. 110-135.

Dittmar, H. (2005a), "Compulsive buying - a growing concern? An examination of gender, age, and endorsement of materialistic values as predictors", British Journal of Psychology, Vol. 96 No. 4, pp. 467-491, doi: 10.1348/000712605X535332017-2352.

Dittmar, H. (2005b), "A new look at 'compulsive buying': self-discrepancies and materialistic values as predictors of compulsive buying tendency", Journal of Social and Clinical Psychology, Vol. 24 No. 6, pp. 832-859, doi: 10.1521/jscp.2005.24.6.832.

Duroy, D., Gorse, P. and Lejoyeux, M. (2014), "Characteristics of online compulsive buying in Parisian students”, Addictive Behaviors, Vol. 39 No. 12, pp. 1827-1830, doi: 10.1016/j.addbeh.2014.07.028.

Elliott, R. and Wattanasuwan, K. (1998), "Consumption and the symbolic project of the self", in Englis, B.G. and Anna, O. (Eds), E - European Advances in Consumer Research, Association for Consumer Research, Vol. 3, pp. 17-20.

Elliott, R. (1994), "Addictive consumption: function and fragmentation in postmodernity", Journal of Consumer Policy, Vol. 17, pp. 159-179, doi: 10.1007/BF01016361.

Eroglu, F. and Kocatürk, E.B. (2020), "Future insights for the role of materialism and money attitudes on online compulsive buying", Yönetim Bilimleri Dergisi/Journal of Administrative Sciences, Vol. 18 No. 38, pp. 887-911, doi: 10.35408/comuybd.692725.

Faber, R.J. (2010), "Impulsive and compulsive buying", in Sheth, J. and Malholtra, N. (Eds), Wiley International Encyclopedia of Marketing, Wiley, pp. 306-312.

Faber, R.J. and Christenson, G.A. (1996), "In the mood to buy: differences in the mood states experienced by compulsive buyers and other consumers", Psychology and Marketing, Vol. 13 No. 8, pp. 803-819, doi: 10.1002/(SICI)1520-6793(199612)13:83.0.CO;2-J.

Faber, R.J. and O'Guinn, T.C. (2008), “Compulsive buying: review and reflection”, in Haugtvedt, C.P., Herr, P.M. and Kardes, F.R. (Eds), Handbook of Consumer Psychology, Routledge, pp. 1039-1056. 
Faber, R.J. and Vohs, K.D. (2004), "To buy or not to buy? Self-control and self-regulatory failure in purchase behaviour", in Baumeister, R.F. and Vohs, K.D. (Eds), Handbook of Self-Regulation, Guilford Press, pp. 509-524.

Faber, R.J. and Vohs, K.D. (2011), "Self-regulation and spending-evidence from impulsive and compulsive buying", in Vohs, K.D. and Baumeister, R.F. (Eds), Handbook of Self-Regulation: Research, Theory and Applications, Guilford Press, pp. 537-550.

Falk, T., Kunz, W.H., Schepers, J.J.L. and Mrozek, A.J. (2016), "How mobile payment influences the overall store price image”, Journal of Business Research, Vol. 69 No. 7, pp. 2417-2423, doi: 10. 1016/j.jbusres.2016.01.011.

Fan, W., Zhong, H. and Zhu, A. (2020), "Destigmatising the stigma: understanding the impact of message framing on Chinese consumers' guilt and attitude associated with overspending behaviour", Journal of Consumer Behaviour, Vol. 20, pp. 7-20, doi: 10.1002/cb.1848.

Feinberg, R.A. (1986), "Credit cards as spending facilitating stimuli: a conditioning interpretation", Journal of Consumer Research, Vol. 12, pp. 384-356, doi: 10.1086/209074.

Gollwitzer, P.M. and Wicklund, R. (1981), "Symbolic self-completion, attempted influence, and selfdepreciation”, Basic and Applied Social Psychology, Vol. 2 No. 2, pp. 89-114, doi: 10.1207/ s15324834basp0202_2.

Harnish, R.J., Bridges, K.R., Nataraajan, R., Gump, J.T. and Carson, A.E. (2018), "The impact of money attitudes and global life satisfaction on the maladaptive pursuit of consumption", Psychology and Marketing, Vol. 35 No. 3, pp. 189-196, doi: 10.1002/mar.21079.

Harnish, R.J., Roche, M.J. and Bridges, K.R. (2021), "Predicting compulsive buying from pathological personality traits, stressors, and purchasing behavior", Personality and Individual Differences, Vol. 177, doi: 10.1016/j.paid.2021.110821.

Hayes, A.F. (2013), Introduction to Mediation, Moderation, and Conditional Process Analysis - A Regression-Based Approach, The Guilford Press, New York.

Hsieh, K.-Y., Hsiao, R.C., Yang, Y.-H., Lee, K.-H. and Yen, C.-F. (2019), "Relationship between selfidentity confusion and internet addiction among college students: the mediating effects of psychological inflexibility and experiential avoidance", International Journal of Environmental Research and Public Health, Vol. 16 No. 17, p. 3225, doi: 10.3390/ijerph16173225.

Jiang, Z. and Shi, M. (2016), "Prevalence and co-occurrence of compulsive buying, problematic Internet and mobile phone use in college students in Yantai, China: relevance of self-traits", BMC Public Health, Vol. 16, p. 1211, doi: 10.1186/s12889-016-3884-1.

Kamleitner, B. and Erki, B. (2013), "Payment method and perceptions of ownership", Marketing Letters, Vol. 24, pp. 57-69, doi: 10.1007/s11002-012-9203-4.

Khandelwal, R., Kolte, A., Veer, N. and Sharma, P. (2021), "Compulsive buying behaviour of credit card users and affecting factors such as financial knowledge, prestige and retention time: a crosssectional research", Vision: The Journal of Business Perspective, pp. 1-9, First Published February 6, doi: 10.1177/0972262920981428.

Khare, A. (2013), "Credit card use and compulsive buying behavior", Journal of Global Marketing, Vol. 26 No. 1, pp. 28-40, doi: 10.1080/08911762.2013.779406.

Kiss, O.E. and Veres, Z. (2017), "Motivational characteristics of online shopping and buying: impulsive and compulsive buying in e-Stores", in Becerra, E.P., Chitturi, R., Daza, M.C.H. and Roldan, J.C.L. (Eds), LA - Latin American Advances in Consumer Research, Association for Consumer Research, Vol. 4, pp. 50-53.

Kyrios, M., Frost, R.O. and Steketee, G. (2004), “Cognitions in compulsive buying and acquisition”, Cognitive Therapy and Research, Vol. 28 No. 2, pp. 241-258, doi: 10.1023/B:COTR.0000021543.62799.32.

Lee, Y.J. and Park, J.K. (2008), "The mediating role of consumer conformity in e-compulsive buying”, in Lee, A.Y. and Soman, D. (Eds), Advances in Consumer Research, Association for Consumer Research, Vol. 35, pp. 387-392.

\section{Internet shopping and compulsive buying}


$\underset{2,1}{\text { JIDE }}$

Lee, S.-H. and Workman, J.E. (2018), "Consumer tendency to regret, compulsive buying, gender, and fashion time-of-adoption groups", International Journal of Fashion Design, Technology and Education, Vol. 11 No. 3, pp. 265-276, doi: 10.1080/17543266.2017.1423518.

Lee, S.-H. and Workman, J.E. (2021), "Trendsetting and gender matter: brand loyalty, perceived quality, and word-of-mouth", Journal of Global Fashion Marketing, Vol. 12 No. 1, pp. 16-31, doi: 10.1080/20932685.2020.1835523.

Lee, S., Park, J. and Lee, S.B. (2016), "The interplay of internet addiction and compulsive shopping behaviors", Social Behavior and Personality: An International Journal, Vol. 44 No. 11, pp. 1901-1912, doi: 10.2224/sbp.2016.44.11.1901.

Liu, Y., Unger, A., Bi, C., Papastamateleou, J. and Raab, G. (2021), "Online compulsive buying as a coping strategy for self-uncertainty: the moderating role of gender in China", Journal of Internet Commerce, Published online: 19 Oct 2021, doi: 10.1080/15332861.2021.1988242.

Livingstone, S.M. and Lunt, P.K. (1992), "Predicting personal debt and debt repayment: psychological, social and economic determinants", Journal of Economic Psychology, Vol. 13 No. 1, pp. 111-134, doi: 10.1016/0167-4870(92)90055-C.

Maccarrone-Eaglen, A. and Schofield, P. (2020), "Compulsive buying among young adults: a behavioural segmentation”, Young Consumers, Vol. 21 No. 1, pp. 57-76, doi: 10.1108/YC-02-2019-0958.

Maraz, A., Griffiths, M.D. and Demetrovics, Z. (2016), "The prevalence of compulsive buying: a metaanalysis", Addiction, Vol. 111 No. 3, pp. 408-419, doi: 10.1111/add.13223.

Mestre-Bach, G., Steward, T., Jiménez-Murcia, S. and Fernández-Aranda, F. (2017), "Differences and similarities between compulsive buying and other addictive behaviors", Current Addiction Reports, Vol. 4 No. 3, pp. 228-236, doi: 10.1007/s40429-017-0153-z.

Moulding, R., Duong, A., Nedeljkovic, M. and Kyrios, M. (2017), "Do you think that money can buy happiness? A review of the role of mood, materialism, self, and cognitions in compulsive buying”, Current Addiction Reports, Vol. 4, pp. 254-261, doi: 10.1007/s40429-017-0154-y.

Moulding, R., Kings, C. and Knight, T. (2021), "The things that make us: self and object attachment in hoarding and compulsive buying-shopping disorder", Current Opinion in Psychology, Vol. 39, pp. 100-104, doi: 10.1016/j.copsyc.2020.08.016.

Mueller, A., Brand, M., Claes, L., Demetrovics, Z., de Zwaan, M., Fernández-Aranda, F., Frost, R.O., Jimenez-Murcia, S., Lejoyeux, M., Steins-Loeber, S., Mitchell, J.E., Moulding, R., Nedeljkovic, M., Trotzke, P., Weinstein, A. and Kyrios, M. (2019), "Buying-shopping disorder-is there enough evidence to support its inclusion in ICD-11?", CNS Spectrums, Vol. 24 No. 4, pp. 374-379, doi: 10. 1017/S1092852918001323.

Mueller, A., Claes, L., Mitchell, J.E., Faber, R.J., Fischer, J. and de Zwaan, M. (2011a), "Does compulsive buying differ between male and female students?", Personality and Individual Differences, Vol. 50 No. 8, pp. 309-1312.

Mueller, A., Mitchell, J.E., Peterson, L.A., Faber, R.J., Steffen, K.J., Crosby, R.D. and Claes, L. (2011b), "Depression, materialism, and excessive internet use in relation to compulsive buying", Comprehensive Psychiatry, Vol. 52, pp. 420-424, doi: 10.1016/j.comppsych.2010.09.001.

Naughton, J. (2000), A Brief History of the Future: The origins of the Internet, Weidenfeld and Nicolson, London.

Neuner, M., Raab, G. and Reisch, L.A. (2005), "Compulsive buying in maturing consumer societies: an empirical re-inquiry”, Journal of Economic Psychology, Vol. 26, pp. 509-522, doi: 10.1016/j.joep. 2004.08.002.

Nga, J.K.H., Yong, L.H.L. and Sellappan, R. (2011), "The influence of image consciousness, materialism and compulsive spending on credit card usage intentions among youth", Young Consumers, Vol. 12 No. 3, pp. 243-253, doi: 10.1108/17473611111163296.

Nofario, E, Purwanto and Hendratono, T. (2020), "The moderating role of credit card usage on the relationship between money power prestige, money distrust, and money anxiety with compulsive buying”, Technology Reports of Kansai University, Vol. 62 No. 10, pp. 6273-6281. 
Otero-López, J. and Villardefrancos, E. (2014), "Prevalence, sociodemographic factors, psychological distress, and coping strategies related to compulsive buying: a cross sectional study in Galicia, Spain”, BMC Psychiatry, Vol. 14 No. 1, p. 101, doi: 10.1186/1471-244X-14-101.

Pradhan, D., Israel, D. and Jena, A.K. (2018), "Materialism and compulsive buying behaviour: the role of consumer credit card use and impulse buying", Asia Pacific Journal of Marketing and Logistics, Vol. 30 No. 5, pp. 1239-1258, doi: 10.1108/APJML-08-2017-0164.

Prelec, D. and Loewenstein, G. (1998), "The red and the black: mental accounting of savings and debt", Marketing Science, Vol. 17 No. 1, doi: 10.1287/mksc.17.1.4.

Prelec, D. and Simester, D. (2001), "Always leave home without it: a further investigation of the creditcard effect on willingness to pay", Marketing Letters, Vol. 12 No. 1, pp. 5-12, doi: 10.1023/A: 1008196717017.

Raab, G. (1998), Kartengestützte Zahlungssysteme und Konsumentenverhalten (Card Based Payment Systems and Consumer Behavior), Duncker and Humblot, Berlin.

Raab, G. and Neuner, M. (2008), "'Kaufsucht im Internet-eine Studie am Beispiel des Kauf- und Auktionsverhaltens auf Ebay" (Compulsive buying in the internet - a study about the case of buying and auction behavior at e-ebay)", NeuroPsychoEconomics, Vol. 3 No. 1, pp. 34-42.

Raab, G., Neuner, M., Reisch, L.A. and Scherhorn, G. (2005), SKSK - Screeningverfahren zur Erhebung von kompensatorischem und süchtigem Kaufverhalten. Manual [SKSK - Screening Procedure for the Measurement of Compensatory and Addictive Buying Behavior. Manual], Hogrefe, Göttingen.

Raab, G., Elger, C., Neuner, M. and Weber, B. (2010), "The neural basis of compulsive buying", in Müller, A., James, A. and Mitchell (Eds), Compulsive Buying: Clinical Foundations and Treatment, Routledge, pp. 83-86.

Raab, G., Elger, C., Neuner, M. and Weber, B. (2011), "A neurological study of compulsive buying behavior”, The Journal of Consumer Policy, Vol. 34, pp. 401-413, doi: 10.1007/s10603-011-9168-3.

Richins, M.L. (2011), "Materialism, transformation expectations, and spending: implications for credit use", Journal of Public Policy and Marketing, Vol. 30, pp. 141-156, doi: 10.2307/23209270.

Ridgway, N.M., Kukar-Kinney, M. and Monroe, K.B. (2008), "An expanded conceptualization and a new measure of compulsive buying", Journal of Consumer Research, Vol. 35 No. 4, pp. 622-639, doi: $10.1086 / 591108$.

Runnemark, E., Hedman, J. and Xiao, X. (2015), "Do consumers pay more using debit cards than cash", Electronic Commerce Research and Applications, Vol. 14 No. 5, pp. 285-291, doi: 10.1016/j.elerap. 2015.03.002.

Scherhorn, G. (1990), “The addictive trait in buying behaviour”, Journal of Consumer Policy, Vol. 13, pp. 33-51, doi: 10.1007/BF00411868.

Scherhorn, G., Reisch, L.A. and Raab, G. (1990), "Addictive buying in West Germany: an empirical study”, Journal of Consumer Policy, Vol. 13, pp. 355-387, doi: 10.1007/BF00412336.

Scherhorn, G., Reisch, L.A. and Raab, G. (1992), "Addictive buying. Further investigations in West and East Germany", Joint Conference on Economic Psychology and Experimental Economics, Frankfurt/Main, Germany, Vol. 27 (30 August 1992).

Sharif, S.P. and Khanekharab, J. (2017), "Identity confusion and materialism mediate the relationship between excessive social network site usage and online compulsive buying", Cyberpsychology, Behaviour and Social Networking, Vol. 20 No. 8, pp. 494-500, doi: 10.1089/cyber.2017.0162.

Sharif, S.P. and Yeoh, K.K. (2018), "Excessive social networking sites use and online compulsive buying in young adults: the mediating role of money attitude", Young Consumers, Vol. 19 No. 3, pp. 310-327, doi: 10.1108/YC-10-2017-00743.

Sharif, S.P., She, L., Yeoh, K.K. and Naghavi, N. (2021), "Heavy social networking and online compulsive buying: the mediating role of financial social comparison and materialism", Journal of Marketing Theory and Practice. doi: 10.1080/10696679.2021.1909425.
Internet
shopping and
compulsive
buying

43 


\section{JIDE 2,1}

She, L., Rasiah, R., Waheed, H. and Sharif, P.S. (2021), "Excessive use of social networking sites and financial well-being among young adults: the mediating role of online compulsive buying", Young Consumers, Vol. 22 No. 2, pp. 272-289, doi: 10.1108/YC-11-2020-1252.

Soll, J.B., Keeney, R.L. and Larrick, R.P. (2013), "Consumer misunderstanding of credit card use, payments, and debt: causes and solutions", Journal of Public Policy and Marketing, Vol. 32 No. 1, pp. 66-81, doi: 10.1509/jppm.11.061.

Soman, D. (2001), "Effects of payment mechanism on spending Behavior: the role of rehearsal and immediacy of payments", Journal of Consumer Research, Vol. 27, pp. 460-474, doi: 10.1086/ 319621.

Statista (2018), Anteil der Online-Käufer an der Bevölkerung nach Ländern weltweit im Jahr 2017 (Percentage of online buyer of the population differentiated to countries worldwide in the year 2017), cited in Zaharia (2019).

Suresh, A.S. and Biswas, A. (2020), "A study of factors of internet addiction and its impact on online compulsive buying behaviour: Indian millennial perspective”, Global Business Review, Vol. 21 No. 6, pp. 1448-1465, doi: 10.1177/0972150919857011.

Tarka, P. (2020), "Influence of materialism on compulsive buying behavior: general similarities and differences related to studies on young adult consumers in Poland and US", Journal of International Consumer Marketing, Vol. 32 No. 3, pp. 243-267, doi: 10.1080/08961530.2019. 1695240.

Trotzke, P., Starcke, K., Müller, A. and Brand, M. (2015), "Pathological buying online as a specific form of internet addiction: a model-based experimental investigation", PLoS One, Vol. 10, e0140296, doi: 10.1371/journal.pone.0140296.

Unger, A., Lyu, H. and Zimbardo, P.G. (2018), "How compulsive buying is influenced by time perspective - cross-cultural evidence from Germany, Ukraine, and China", International Journal of Mental Health and Addiction, Vol. 16 No. 3, pp. 525-544, doi: 10.1007/s11469-018-4.9942-4.

Unger, A. and Raab, G. (2015), "The dark side of globalization and consumption: how similar are Chinese and German consumers toward their proneness to compulsive buying?", Journal of Asia-Pacific Business, Vol. 16 No. 1, doi: 10.1080/10599231.2015.997624.

VuMA (2020), "Umfrage zu Online-Käufern in Deutschland nach Geschlecht 2019” [Survey in "Germany about online-shopping in the internet differentiated by gender 2019]", Statista, available at: https:/de.statista.com/statistik/daten/studie/538396/umfrage/online-kaeufer-indeutschland-nach-geschlecht/.

VuMA (2021), “'Umfrage in Deutschland zu Online-Shopping im Internet nach Geschlecht 2020" [Survey in Germany about online-shopping in the internet differentiated by gender2020]", Statista, available at: https:/de.statista.com/statistik/daten/studie/313057/umfrage/umfrage-indeutschland-zu-online-shopping-im-internet-nach-geschlecht/.

Wang, C.-C. and Yang, H.-W. (2008), "Passion for online shopping: the influence of personality and compulsive buying", Social Behavior and Personality, Vol. 36 No. 5, pp. 693-706, doi: 10.2224/ SBP.2008.36.5.6932224/sbp.2008.36.5.693.

Wang, X., Ali, F., Tauni, Z.M., Zhang, Q. and Ahsan, T. (2021), "Effects of hedonic shopping motivations and gender differences on compulsive online buyers", Journal of Marketing Theory and Practice, pp. 1-17, doi: 10.1080/10696679.2021.1894949.

Weinstein, A., Mezig, H., Mizrachi, S. and Lejoyeux, M. (2015), "A study investigating the association between compulsive buying with measures of anxiety and obsessive-compulsive behavior among internet shoppers", Comprehensive Psychiatry, Vol. 57, pp. 46-50, doi: 10.1016/j. comppsych.2014.11.003.

Wicklund, R.A. and Gollwitzer, P.M. (1982), Symbolic Self-completion, L. Erlbaum Associates, Hillsdale.

Wong, K.-Y. and Lynn, M. (2017), "The easy-money effect: credit card spending and hard-work reminders", Journal of Consumer Marketing, Vol. 34 No. 7, pp. 541-551, doi: 10.1108/JCM-072016.1868 . 
Workman, L. and Paper, D. (2010), "Compulsive buying: a theoretical framework", The Journal of Business Inquiry, Vol. 9 No. 1, pp. 89-126.

Yu, Y., Li, O. and Wang, L. (2020), "The psychological mechanisms and influencing factors of the payment effect", Chinese Journal of Applied Psychology, available at: http://appliedpsy.cn/EN/ abstract/abstract289.shtml.

Zaharia, S. (2019), "Online shopping motives - an empirical investigation of consumer buying behavior in Germany's main online retail segments", in Nah, F.F.H. and Siau, K. (Eds), HCI in Business, Government and Organizations. Ecommerce and Consumer Behavior. HCII 2019. Lecture Notes in Computer Science, Springer, Heidelberg, Vol. 11588.

Zhang, J., Bai, Z., Wei, J., Yang, M. and Fu, G. (2019), “The status quo of college students' online shopping addiction and its coping strategies", International Journal of Psychological Studies, Vol. 11 No. 2, pp. 88-93, doi: 10.5539/ijps.v11n2p88.

Zheng, Y., Yang, X., Liu, Q., Chu, X., Huang, Q. and Zhou, Z. (2020a), "Perceived stress and online compulsive buying among women: a moderated mediation model", Computers in Human Behavior, Vol. 103, pp. 13-20, doi: 10.1016/j.chb.2019.09.012.

Zheng, Y., Yang, X., Zhou, R., Niu, G., Liu, Q. and Zhou, Z. (2020b), "Upward social comparison and state anxiety as mediators between passive social network site usage and online compulsive buying among women", Addictive Behaviors, Vol. 111, p. 106569, doi: 10.1016/j.addbeh.2020. 106569 .

\section{Corresponding author}

Chongzeng Bi can be contacted at: beech@swu.edu.cn
Internet shopping and compulsive buying

For instructions on how to order reprints of this article, please visit our website:

www.emeraldgrouppublishing.com/licensing/reprints.htm

Or contact us for further details: permissions@emeraldinsight.com 